\title{
A Low-Cost Inkjet-Printed Paper-Based Potentiostat ${ }^{\dagger}$
}

\author{
Petroné Bezuidenhout ${ }^{1,2, *}$, Suzanne Smith ${ }^{2}$ (i) and Trudi-Heleen Joubert ${ }^{1}$ \\ 1 Carl and Emily Fuchs Institute for Microelectronics (CEFIM), University of Pretoria, Pretoria 0002, \\ South Africa; trudi.joubert@up.ac.za \\ 2 Materials Science and Manufacturing, Council for Scientific and Industrial Research (CSIR), Pretoria 0184, \\ South Africa; ssmith@csir.co.za \\ * Correspondence: u11038757@tuks.co.za; Tel.: +27-12-841-4899 \\ + This is an extended version of the article in the proceedings of Miniaturized Systems for Chemistry and Life \\ Sciences (MicroTAS 2017).
}

Received: 15 May 2018; Accepted: 5 June 2018; Published: 13 June 2018

Featured Application: An electrochemical reader developed with the aim to create a low-cost disposable, maintenance-free and user-friendly point-of-need sensing system.

\begin{abstract}
The work presented details the manufacturing of a low-cost hybrid inkjet-printed paper-based potentiostat, with the aim of creating a low-cost sensing system for rapid water quality monitoring. Potentiostats exhibit high sensitivities and can be used for a variety of applications. The results highlight the functionality of a paper-based potentiostat compared to a potentiostat manufactured on a printed circuit board (PCB), an LMP91000EVM development board and a laboratory-based Metrohm Autolab potentiostat. Cyclic voltammetry was performed using an $80 \mu \mathrm{L}$ sample of $5 \mathrm{mM}$ ferri-ferrocyanide dropped onto a commercial screen-printed electrode from DropSens. The miniaturized paper-based potentiostat is small enough to be stored in a wallet and therefore easy to transport. Furthermore, a cost analysis shows that the potentiostat is 10 times lower in cost than the commercially available handheld potentiostat, taking the costs of man hours into account. This technology enables electrochemistry experiments to be performed on-site using the portable, disposable and low-cost solution and can be applied to a variety of fields including healthcare, wearables and environmental monitoring.
\end{abstract}

Keywords: potentiostat; point-of-need; LMP91000; low-cost; printed electronics; paper-based

\section{Introduction}

The focus of this paper is on the development of a low-cost inkjet-printed paper-based sensing system that produces comparable results to that of a laboratory-based potentiostat. Various educational, environmental, healthcare, energy provision and storage challenges exist that can benefit from a point-of-need, effective, low-cost, user-friendly and portable solution [1-3]. The ASSURED criteria established by the World Health Organization stipulates that point-of-need solutions should be Affordable, Sensitive, Specific, User-friendly, Rapid and Robust, Equipment free and Deliverable to end-users [4]. Advantageous properties of paper, such as disposability and low cost, provide a favorable platform on which to implement diagnostic tools, aligning well with the ASSURED criteria [4-8].

The advantages of paper include processing versatility allowing for broad application areas. Furthermore, compared to paper, other substrates such as Polyethylene terephthalate (PET) and Polyethylene naphthalate (PEN) are not as suited for remote environmental monitoring when considering the increase in substrate cost, and the environmental impact of these oil-based materials [9]. The cost of commercial resin coated paper used in printed electronics are approximately a sixth of the 
cost of PET, enabling paper to be further optimized and/or customized without exceeding the cost of PET [9]. These customizations enable the integration of paper-based microfluidics and paper-based electronics, used for a variety of environmental and health applications. Various researchers have focused on smart papers that have both hydrophobic and hydrophilic properties to accommodate both liquid flow and printed electronics, enabling smart, low-cost, point-of-need sensors and biosensing systems to be realized in fields such as water monitoring $[2,10]$.

Conformal printing technologies are important where electronic circuits must be printed on or around three-dimensional objects, such as in hybrid integration of three-dimensional components with printed electronics circuits on flexible substrates. Challenges created include local defects on high curvature areas. An example of a potentiostat integrated on a mouthguard highlighted the integration challenges between flexible substrates and rigid components, as well as the conductive adhesion between different substrates $[1,11]$. Inkjet printing is a contactless deposition method that does not require patterning masks, and is therefore ideally suited to direct printing on a variety of non-planar substrates [12]. Furthermore, the use of inkjet printing to print on water soluble substrates have been reported, which allows conformal printing that directly adheres to any three-dimensional object [13], advancing the ubiquitous use of printed electronics technologies. Fields investigated in non-planar printing include applications such as gas chromatography, as well as electronic noses and electronic tongues, which have been successfully used to perform food freshness evaluations. These applications broaden the utilization scope of a printed point-of-need potentiostat [12]. The investigation of conformal printing challenges in hybrid printed electronics integration formed part of prior work, which contributed to the development of the low-cost inkjet-printed potentiostat presented in this work $[7,14,15]$. Commercial off-the-shelf components were connected to a paper substrate using inkjet-printing to create non-planar connections. The flexibility of the silver tracks and connections were verified by bending the various circuits consisting of surface mount components around a $31 \mathrm{~mm}$ diameter object in different directions. The number of effective connections between the components and circuits before the bending test and after the bending procedure were the same, validating the proof of concept [7]. Other authors have reported on silver tracks on paper being bent around a $1.5 \mathrm{~mm}$ radius during a 10,000 cycle bending test [16].

Potentiostats use stripping analyses to detect electrochemically active analytes in a sample. A varying potential applied to an electrode results in the measured current flowing through the electrochemical cell. The applied potential causes the analyte to oxidize or reduce at the sensor surface, therefore changing the concentration of the electroactive species and causing the measured current change. Potentiostats are dynamic, robust, have a high sensitivity, and can produce large organic and inorganic linear concentration curves $[17,18]$. Potentiostats can also measure more than one analyte simultaneously $[17,18]$. This allows for a wide range of analyte detection including ethanol, gas and heavy metal detection, as well as biosensing. For these reasons, studies focusing on potentiostats for point-of-need applications have increased rapidly in the past few years [2,3,19-24].

The integration of off-the-shelf silicon components and paper-based substrates allows for parallel development, low cost manufacturing, and rapid prototyping $[5-8,25,26]$. The well-established silicon platform allows the use of off-the-shelf potentiostat chips together with user-friendly processors such as Beetle board [27], Arduino [28], and Raspberry Pi [29], to create a lower cost solution [14,15]. This decreases the price of a potentiostat by more than a factor of 10 in comparison to laboratory equipment $[30,31]$. Another hybrid printed potentiostat example include an integrated biosensor platform that was screen-printed on an PET substrate and displayed the detected glucose levels on an electrochromic display [6]. Portable potentiostats are available, but when considering a device that can be manufactured in volume, is disposable and maintenance free, these portable potentiostats are still expensive [32] for pervasive deployment.

Other important factors to take into account when developing a low-cost device include initial cost, maintenance, and user-friendliness of the software, and therefore freeware such as 
Gobetwino [33] on the open-source Arduino [29] was selected for the development of the low-cost point-of-need potentiostat.

A potentiostat front-end was manufactured on a paper substrate and compared to a prototype of the device manufactured on a printed circuit board (PCB), an off-the-shelf potentiostat front-end development board, and a laboratory-based potentiostat instrument [14,15]. Cyclic voltammetry was performed using a $5 \mathrm{mM}$ ferri-ferrocyanide $80 \mu \mathrm{L}$ sample dropped onto a commercial screen-printed electrode. The paper-based potentiostat displayed similar contour characteristics to those of the PCB potentiostat, development board and the laboratory-based potentiostat. The oxidation and redox peaks validated the paper-based potentiostat, which are indicators of electron transfer characteristics.

\section{Materials and Methods}

\subsection{Materials and Manufacturing}

Figure 1 is an illustration, including photographic images of the connected components, of the fabrication process followed to manufacture the paper-based potentiostat.

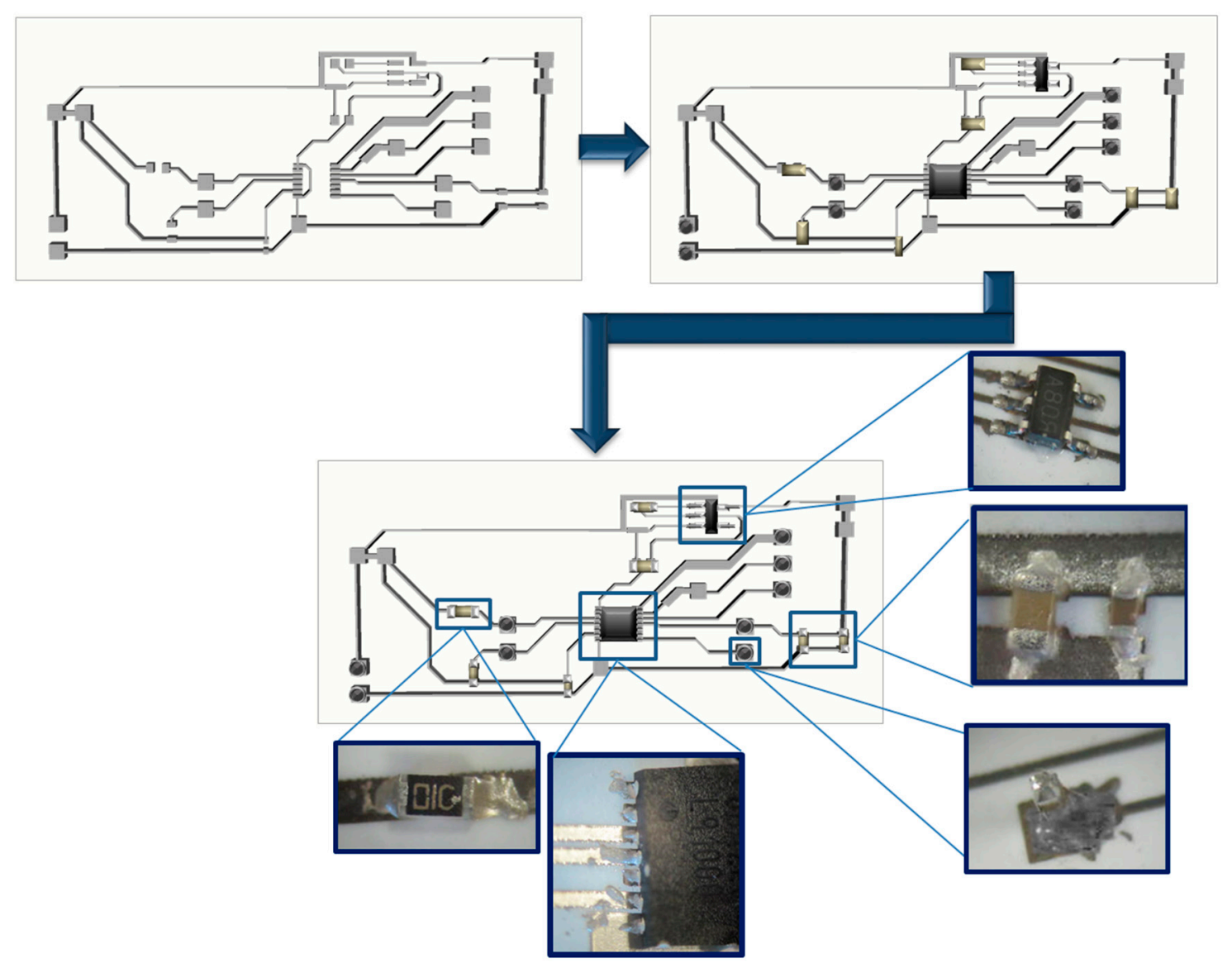

Figure 1. A flow diagram of the steps followed to fabricate the printed paper-based potentiostat.

The global interconnections of the paper-based potentiostat consist of conductive tracks and component pads that were inkjet-printed with a nanosilver ink (NPS-JL, Harima Chemicals, Tokyo, Japan) onto a photo paper substrate (NB-RC-3GR120, Mitsubishi, Tokyo, Japan) using a drop-and-demand piezo inkjet-printer (DMP-2831 Materials printer, Dimatix, Santa Clara, CA, USA). Printing was performed using a single nozzle, jetting at $40 \mathrm{~V}$, a nozzle temperature of $28^{\circ} \mathrm{C}$ and a platen temperature of $30^{\circ} \mathrm{C}$. This was followed by a thermal curing step at a $100{ }^{\circ} \mathrm{C}$ for an hour in a convection oven (276 digital EcoTherm convection oven, Labotec, Midrand, South Africa). Surface 
mount components were mechanically connected to the paper substrate using Superglue (Precision Superglue ${ }^{\circledR}$, Henkel Loctite, Düsseldorf, Germany) and the through-hole pin connectors were adhered to the paper using an $0.9 \mathrm{~mm}$ needle and Superglue. The components were electrically connected by hand-painted silver conductive paste (CircuitWorks Conductive Epoxy, Chemtronics, Kennesaw, GA, USA). The process was concluded by a $10 \mathrm{~min}$ curing step at $66^{\circ} \mathrm{C}$ in the convection oven.

The effectiveness of the tracks and connections were validated using a multimeter (Agilent U1242B True RMS Multimeter, Agilent technologies, Santa Clara, CA, USA), and track parameters were characterized in detail using an impedance analyzer (GW-Instek LCR-8110G, New Taipei City, Taiwan). The LCR measurement instrument was connected to the tracks via $1 \mathrm{~mm}$ round-tip pogo pins. DC four-point probing, with calibration on the pogo pins, was used to characterize and compare the resistance of the silver tracks printed on paper substrate to that of copper PCB tracks.

The Fujifilm-supplied ACE7000 software permits the conversion of layout data in various design formats to a pattern file, which the Dimatix printer uses. Therefore, direct transfer from the design of the PCB potentiostat to a paper-based design is possible as illustrated in Figure 2. This approach enables parallel product development, allowing the paper-based circuitry and back-end development to occur independently, and then integrated.

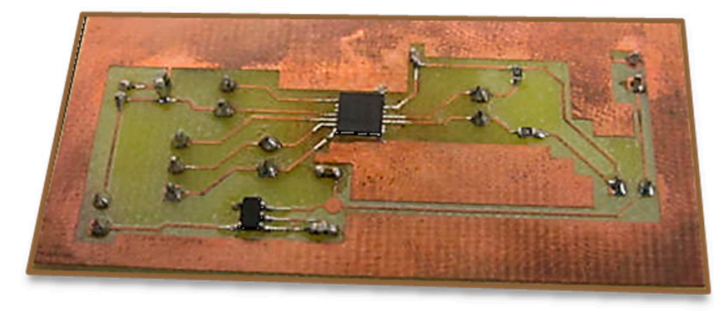

(a)

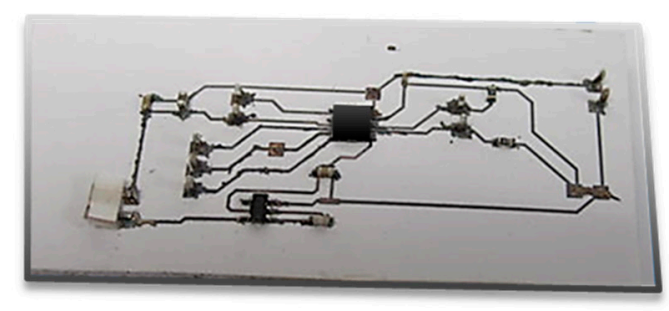

(b)

Figure 2. (a) Printed Circuit Board (PCB) potentiostat, and (b) the Paper-based potentiostat.

The paper-based potentiostat, the PCB potentiostat and the development board (LMP91000EVM, Texas Instruments, Dallas, TX, USA) consist of a sensing chip (LMP91000, Texas Instruments, USA) and required electronic circuitry connected to an Arduino Uno (Arduino, Ivrea, Turin, Italy) which controls and communicates with the potentiostat front-end. The Arduino Uno transmits the sensor data to a personal computer (PC) where the data is saved to a Microsoft Excel (2010) template file and graphed. The results of each system were compared to the results obtained from the laboratory-based potentiostat (Autolab PGSTAT, Metrohm, Germany).

An $80 \mu \mathrm{L}$ sample of $5 \mathrm{mM}$ ferri-ferrocyanide $\left([\mathrm{Fe}(\mathrm{CN}) 6]^{3-/ 4-}\right)$ redox coupled with $0.1 \mathrm{M}$ potassium chloride $(\mathrm{KCl})$ electrolyte was drop-cast onto a commercially available screen-printed carbon ceramic electrochemical sensor (DS-C110, Dropsens, Asturias, Spain) for each experiment.

\subsection{Experimental Procedures}

Using a drop sensing approach, the sample was dispensed onto the center of the three-electrode sensor surface, and three sets of cyclic voltammograms were generated using either the paper-based potentiostat, the PCB potentiostat, the development board or the Autolab. The Metrohm Autolab is a laboratory-based potentiostat/galvanostat system allowing for a wide current range and high resolution. However, for point-of-need applications a tradeoff exists to allow for cost effectiveness and portability, and therefore in this work the Autolab is used to validate the results of the lower cost devices. For the application here, the main focus will be on voltammetry, with emphasis on cyclic voltammetry. Cyclic voltammetry was performed by cycling the potentiostat input potential from negative to positive, and back from positive to negative, while monitoring the output current of the sensing device. 


\subsection{Design and Development of the Potentiostat}

The registers of the PCB potentiostat, paper-based potentiostat and development board potentiostat front-end were programmed using the Arduino UNO via Inter-Integrated Circuit (I2C) communication. The registers control functions such as input waveform generation and gain for the electrochemical experiment. The Reference Control register (REFCN) allocates the input waveform biasing sign and level, the internal zero and voltage source selection. A $50 \%$ biasing point was selected due to the expected reversible cyclic voltammograms (oxidation and redox current peaks have similar absolute heights) [34]. The transimpedance amplifier resistance, $R_{\text {TIA }}(35 \mathrm{k} \Omega)$, and the load impedance $(10 \Omega$ ) were selected using the Transimpedance Control register (TIACN). The input signal was swept from a negative to a positive voltage by stepping the REFCN register from $0 \%$ to $24 \%$ of the supply voltage (Vcc) and varying the bias sign, creating a voltage window ranging from $-0.6 \mathrm{~V}(-24 \% \mathrm{Vcc})$ to $0.6 \mathrm{~V}(+24 \% \mathrm{Vcc})$. The $2.5 \mathrm{~V}$ reference voltage $\left(\mathrm{V}_{\text {ref }}\right)$ created the internal zero around $1.25 \mathrm{~V}$, as well as a voltage range of $1.2 \mathrm{~V}$ containing 48 steps, which generates an input voltage step size of $25 \mathrm{mV}$. Therefore, a $50 \mathrm{mVs}^{-1}$ scan rate is achieved by stepping once every $500 \mathrm{~ms}$ [14]. The voltage output signal $\left(V_{\text {out }}\right)$ of the sensing chip is translated to the output current $\left(I_{\text {out }}\right)$ using Equation (1) [31].

$$
\mathrm{I}_{\mathrm{out}}=\frac{\left(\mathrm{V}_{\mathrm{out}}-\frac{\mathrm{V}_{\mathrm{ref}}}{2}\right)}{\mathrm{R}_{\mathrm{TIA}}}
$$

The second function of the Arduino was to communicate the resulting data to the PC for data analysis. A freeware program called Gobetwino [33] was utilized to prompt the Arduino to start the experiment, and to save and automatically plot the data in a personalized Microsoft ${ }^{\circledR}$ Excel template file.

Figure 3 illustrates the development of the paper-based potentiostat from the laboratory-based approach using the Metrohm Autolab to the development board, the PCB potentiostat, and to the paper-based potentiostat.

From the Autolab benchtop potentiostat to the development board potentiostat, the size reduction is due to the need for portability. Producing a further size reduction as illustrated in Figure 3, the Arduino Uno can perform similar functions to that of the built-in analog-to-digital converter (ADC) and electrically erasable programmable read-only memory (EEPROM) circuit on the development board, allowing the PCB and paper-based potentiostat to consist only of the LMP91000 chip, voltage reference and relevant passive components. If an external reference voltage provided by the Arduino UNO is used, the voltage reference can also be excluded, which simplifies the circuit further. With every step in the progress towards a printed paper-based potentiostat, both the size and the price are reduced, as depicted in Table 1. Although they are not included in the performance comparison of this work, for the sake of interest Table 1 also includes the price and size of two commercially available handheld potentiostats, the Palmsens 3 [35] and the DY2100 Mini potentiostat [32].

Due to uncertainty in supply-chain budgets, the costs given in Table 1 cannot be directly compared, but they do provide general cost considerations. It should be noted that all potentiostats include the total cost for all components except the PC. Furthermore, the PCB and paper potentiostat data include the work costs of a junior research engineer to manufacture the potentiostats. However, this price would decrease significantly if the paper-based potentiostat were to be mass produced. Between $\$ 6.7$ to $\$ 8.9$ would be added to the cost of the development board, PCB potentiostat and paper-based potentiostat if the PC is substituted with a display such as an LCD TFT 1.8-inch screen module and a $9 \mathrm{~V}$ battery [36,37]. When taking the approximate costs of the screen and battery into account the cost of the PCB and paper-based potentiostat is still much lower than the Palmsens 3 and DY2100 mini potentiostat. 
Progress From lab-based potentiostat to hybrid paper-based potentiostat

Lab-based potentiostat using:

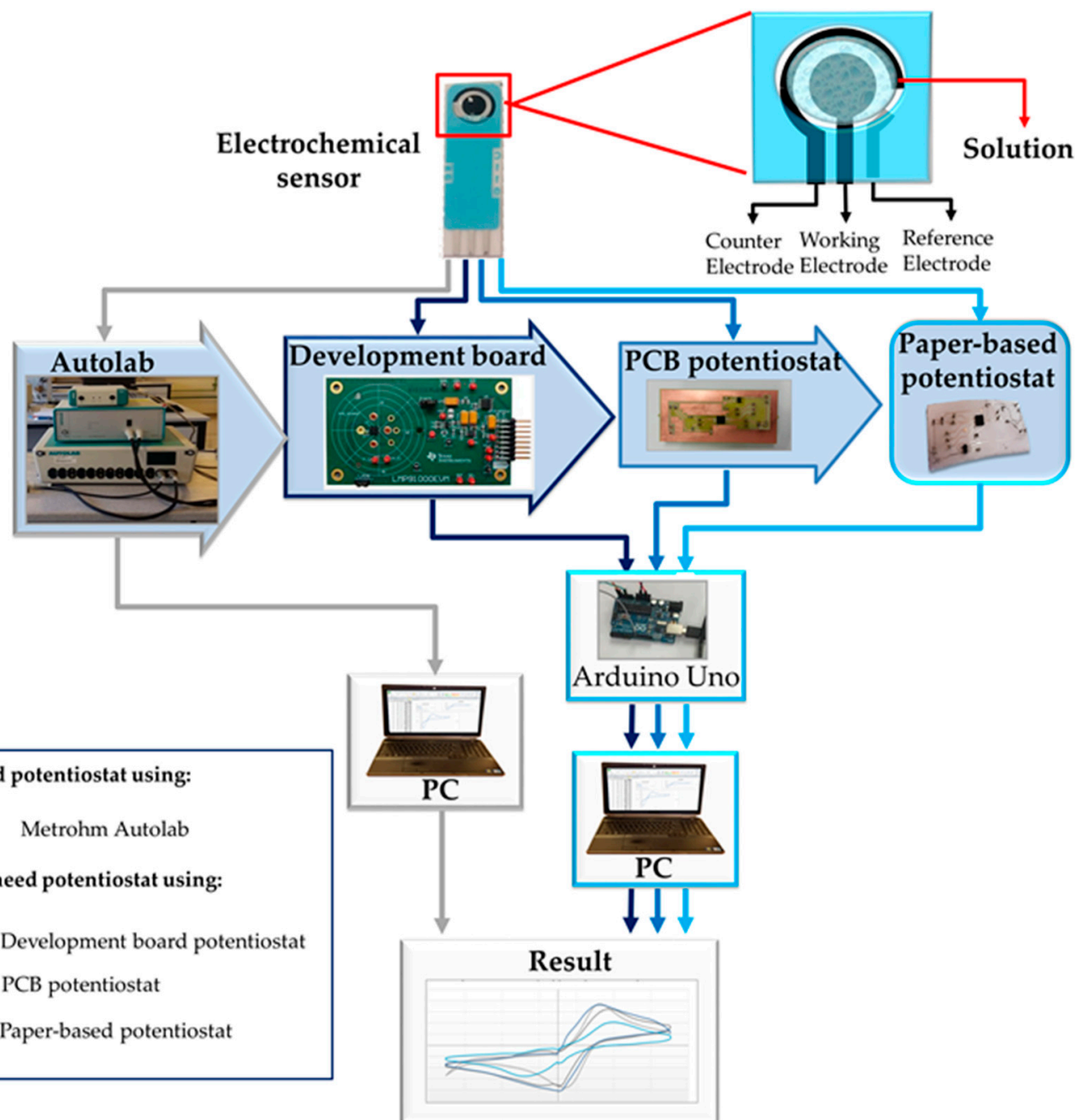

Figure 3. A development diagram of the point-of-need potentiostat, depicting the development towards a printed paper-based potentiostat the process followed by the Autolab to generate a result, and the process followed by the development board, the PCB potentiostat and the paper-based potentiostat to produce a result.

Table 1. Footprint and cost reduction as the development of the paper-based potentiostat progresses.

\begin{tabular}{ccccccc}
\hline Autolab [38] & $\begin{array}{c}\text { Palmsens 3 } \\
{[35]}\end{array}$ & $\begin{array}{c}\text { DY2100 } \\
\text { Mini } \\
\text { Potentiostat } \\
{[32]}\end{array}$ & $\begin{array}{c}\text { Development } \\
\text { Board } \\
\text { Potentiostat } \\
{[39,40]}\end{array}$ & $\begin{array}{c}\text { Printed } \\
\text { Circuit } \\
\text { Board (PCB) } \\
\text { Potentiostat } \\
{[40-42]}\end{array}$ & $\begin{array}{c}\text { Paper-Based } \\
\text { Potentiostat } \\
{[40,42]}\end{array}$ \\
\hline $\begin{array}{c}\text { Footprint } \\
\text { volume } \\
\text { Cost }\end{array}$ & $34994 \mathrm{~cm}^{3}$ & $461.3 \mathrm{~cm}^{3}$ & $294 \mathrm{~cm}^{3}$ & $70.76 \mathrm{~cm}^{3}$ & $7.14 \mathrm{~cm}^{3}$ & $7.14 \mathrm{~cm}^{3}$ \\
& $>\$ 40,000$ & $\approx \$ 4430$ & $\approx \$ 830$ & $\approx \$ 210$ & $\approx \$ 29$ & $\approx \$ 27$ \\
\hline
\end{tabular}

The paper-based potentiostat is small enough to fit in a wallet, and subsequently easy to transport. The disposability allows the user to either re-use or dispose of the potentiostat. This forms part of the development towards a printed hybrid paper-based sensing solution for low-cost point-of-need water monitoring. 


\section{Results}

Since the resistance of interconnection tracks contribute to the performance of circuits fabricated with different manufacturing methods, a comparison of PCB copper tracks and inkjet-printed silver tracks is requisite. The resistivity and conductive layer thickness will not be same for the two types of tracks, indicating sheet resistance as a logical figure of merit. Nevertheless, in this work the conductive network artwork is the same for the two circuits, rendering the resistance of tracks with the same planar dimensions a more reasonable basis of comparison. Figure 4 shows the experimental results of a PCB copper track and a conductive silver track printed on a paper substrate, both with a width of $300 \mu \mathrm{m}$ and a length of $8 \mathrm{~mm}$.

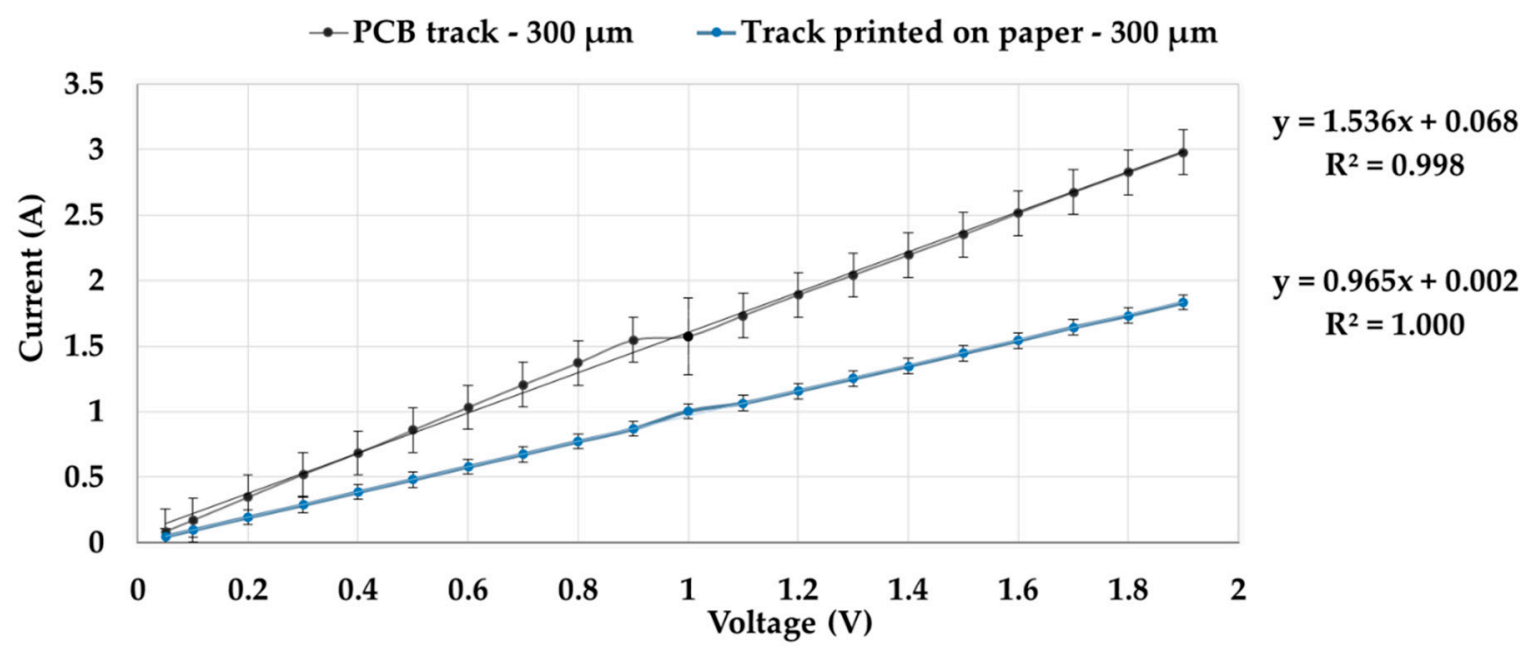

Figure 4. Current-voltage transfer curves for a PCB track and a silver inkjet-printed track on paper of equal planar dimensions.

Figure 4 indicates that both the PCB and printed track have a linear region over the full $2 \mathrm{~V}$ voltage range of the impedance analyzer, which is adequate for the potentiostat application under consideration here. The discontinuity around the $1 \mathrm{~V}$ input voltage is attributable to voltage range switching in the measurement instrument, but was not corrected for in the linear regression for the extraction of resistance values. The resistance of the printed silver track is approximately $160 \%$ of the resistance of the copper PCB track. As an interesting aside, the results of Figure 4 indicate significantly better contact resistance on the printed silver track than on the copper PCB track. Although not confirmed yet, it is conjectured that the round-tip measurement pogo pins indent the more pliable silver to provide a larger contact surface.

The electrochemical performance of the potentiostats on paper and PCB, and also the development board potentiostat, is validated and compared to that of the Autolab in Figure 5, by performing three sets of cyclic voltammetry tests at a $50 \mathrm{mVs}^{-1}$ scan rate for each sensing system, on three identical Dropsens electrodes using a $0.1 \mathrm{M}$ KCL solution containing $5 \mathrm{mM}[\mathrm{Fe}(\mathrm{CN}) 6]^{3-/ 4-}$. The curve of the Autolab indicates a reversible system due to the similar absolute values obtained for redox and oxidation currents [34]. Table 2 investigates the result further by comparing the average and standard deviation of the current peak heights for each set of experiments. The cyclic voltammetry contour of the redox and oxidation currents of the four systems are similar and the standard deviation of each system is less than $10 \%$, indicating that even though the development board, PCB potentiostat and paper-based potentiostat may require further optimization, each of the systems shows repeatability across the experiments performed. 




Figure 5. Comparison of the cyclic voltammograms generated from the average of three experiments using either the Autolab (grey), development board (black), PCB (dark blue), or the paper-based (cyan) potentiostat. The red markers indicate the peak redox and oxidation currents of each sensing system including the accompanying error bars.

Table 2. The average (AVG) and standard deviation (SD) obtained from three repeats of each experiment showcased in Figure 5 using the Autolab, development board and prototype potentiostat, as well as the paper-based potentiostat.

\begin{tabular}{ccccccccc}
\hline & \multicolumn{2}{c}{ Autolab } & \multicolumn{2}{c}{ Development Board } & \multicolumn{2}{c}{ PCB Potentiostat } & \multicolumn{2}{c}{ Paper Potentiostat } \\
\cline { 2 - 8 } & AVG & SD & AVG & SD & AVG & SD & AVG & SD \\
\hline $\begin{array}{c}\text { Redox current } \\
\text { peak }(\mu \mathrm{A})\end{array}$ & 35.2 & 2.4 & 31.7 & 1.3 & 37.5 & 0.7 & 22 & 1.1 \\
$\begin{array}{c}\text { Oxidation current } \\
\text { peak }(\mu \mathrm{A})\end{array}$ & -34.7 & 3.7 & -40.4 & 5.1 & -41.0 & 1.3 & -27.5 & 0.1 \\
\hline
\end{tabular}

In Figure 5, the paper-based potentiostat, PCB potentiostat and development board produce more signal noise than produced by the Autolab. The vertical discontinuity in data that occurs when the input potential is zero for the paper-based potentiostat, PCB potentiostat and development board is due to noise generated by the change in sign of the LMP91000 chip registers. The paper-based potentiostat produces similar results to the other potentiostats, but exhibits a smaller amplitude current signal due to the higher circuit resistance. The current amplitude ratio between the paper-based and PCB potentiostats correlates well with the resistance ratio results presented in Figure 4 . Voltage drops across the network tracks cause a potential difference between the sensor electrodes and the potentiostat chip, which will cause an apparent shift in the oxidation and reduction peak potentials. Particularly if these potential differences are in the same order of magnitude as the solution ohmic drops, the peak potentials will be inaccurate. The change in experimental conditions indicates that for the paper-based potentiostat, the given scan rate may no longer be optimum. Future work will address these issues and further improve the performance of the paper-based potentiostat. 


\section{Conclusions}

The development of a paper-based device towards a low-cost, printed point-of-need potentiostat has been presented that could contribute in a variety of applications. Some initial experimentation has shown that the opportunity exists to perform various electrochemistry experiments using the paper-based potentiostat, which would otherwise need to be performed in a laboratory using expensive, large and specialized equipment or using relatively expensive commercial handheld potentiostats. Although optimization is still required, the developed paper-based potentiostat delivers promising results, similar to those produced by a lab-based potentiostat.

The paper-based potentiostat in Figure 6 consists of an inkjet-printed paper-based sensor port and an inkjet-printed paper-based USB port, of which the first connects to the sensor temporarily (so that various sensors can be used) and the second connects to an Arduino microprocessor, as illustrated in Figure 3. The aim is to integrate the Arduino on to paper in future and use the paper-based USB port to connect to a smart device (smartphone, laptop, desktop etc.). The paper-based potentiostat tracks and connections can be inkjet-printed using silver and dielectric ink (pin connections, insulation layers, and circuit tracks) and populated with off-the-shelf silicon chips.

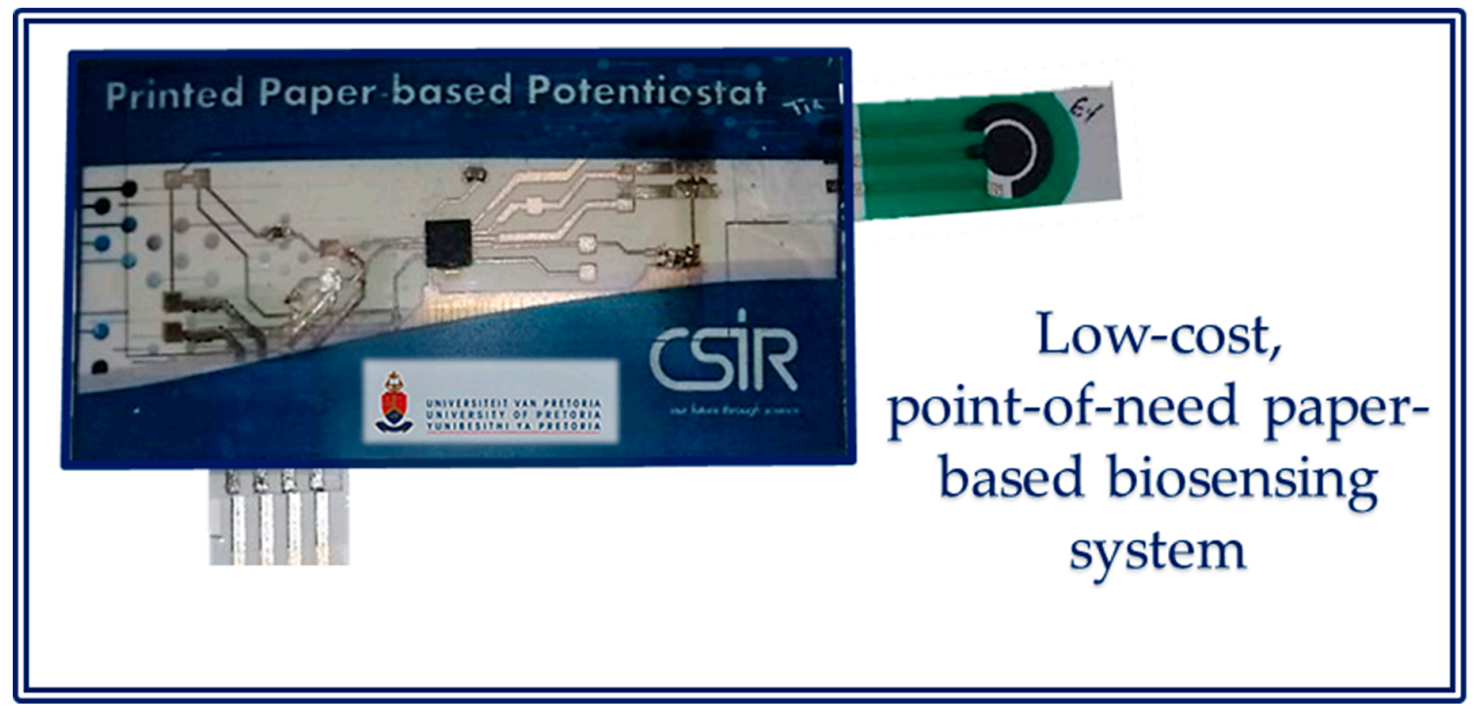

Figure 6. The packaged paper-based potentiostat including a custom-made paper-based sensor connected via paper-connections (Reprinted with permission from the Proceedings of the 13th Edition of IEEE AFRICON 2017, Copyright (C) 2018 IEEE [7]).

The miniaturized paper-based potentiostat in Figure 6 is low-cost, disposable and allows for point-of-need electrochemistry experiments. By utilizing ink-jet printing, it allows for the manufacturing to be fully automated in future. The miniaturized paper-based potentiostat is small enough to be stored in a wallet and is easy to transport and a costing analysis shows that the paper-based potentiostat costs significantly less than the price of the commercially available handheld potentiostat, even when taking manufacturing work costs into account. With continued development and mass manufacturing the cost will decrease further. This system will allow the user to perform electrochemical experiments on-site and have the option to either dispose of or reuse this portable, disposable and low-cost solution. In the case that data is only required to be stored and later analyzed, a laptop USB port is sufficient to power the device, as well as various portable power sources such as coin cells, off-the-shelf AA batteries, or printed flexible batteries. Wireless communication of results is also a future possibility.

The additive nature of manufacturing the potentiostat allows for the addition of other modules such as a card sized Arduino board, a display and a battery. Furthermore, by printing each module, full 
manufacturing automation can be realized in future. Parts of the system would remain customizable depending on the application. Furthermore, the design used for the prototype PCB potentiostat front-end was used directly to manufacture an inkjet-printed circuit, illustrating the ease of technology integration and support of rapid prototyping. Inkjet-printing enables conformal electronics creating the possibility to apply this technology for various scenarios. Likewise, the versatility of potentiostats allow the investigation of various analytes using the paper-based potentiostat. The next steps include testing a hybrid paper-based low-cost potentiostat for environmental monitoring applications.

\section{Patents}

A patent application (Application number: 1717259.4) has been submitted to the United Kingdom patent office regarding this work.

Author Contributions: Conceptualization, T.-H.J., S.S. and P.B.; Methodology, P.B., T.-H.J. and S.S.; Software, P.B. and S.S.; Validation, P.B.; Formal Analysis, P.B. and T.-H.J.; Investigation, P.B.; Resources, P.B. and S.S.; Data Curation, P.B.; Writing-Original Draft Preparation, P.B. and S.S.; Writing-Review \& Editing, T.-H.J.; Visualization, P.B., S.S. and T.-H.J.; Supervision, T.-H.J.; Project Administration, P.B.; Funding Acquisition, P.B. and T.-H.J.

Funding: The authors gratefully acknowledge the Council for Scientific and Industrial Research (CSIR) in Pretoria for funding the project, including funding this work under the YREF (Young Researcher Establishment Fund) and the CSIR SRP (Strategic Research Panel) thematic project. This work is based on the research supported by the National Research Foundation (NRF). Any opinion, finding and conclusion or recommendation expressed in this material is that of the author(s) and the NRF does not accept any liability in this regard.

Acknowledgments: The authors gratefully thank Kevin Land of the CSIR for valuable suggestions and advice in this project.

Conflicts of Interest: The authors declare no conflict of interest.

\section{References}

1. Das, R. Printed, Flexible and Hybrid Electronics: Hot Trends and Market Outlook; IDTechEX Webinar: Cambridge, UK, 2017.

2. Turner, A.P.F. The Paper Potentiostat. In Proceedings of the 4th International Conference on Biosensing Technology, Lisbon, Portugal, 10-13 May 2015.

3. Kim, J.; Jeerapan, I.; Imani, S.; Cho, T.; Bandodkar, A.; Cinti, S.; Mercier, P.; Wang, J. Noninvasive alcohol monitoring using a wearable tattoo-based iontophoretic-biosensing system. ACS Sens. 2016, 1, 1011-1019. [CrossRef]

4. Mabey, D.; Peeling, R.W.; Ustianowski, A.; Perkins, M. Diagnostics for the developing world. Nat. Rev. 2004, 2, 231-240. [CrossRef] [PubMed]

5. Yang, G.; Xie, L.; Mantysalo, M.; Chen, J.; Tenhunen, H. Bio-Patch design and implementation based on a low-power system-on-chip and paper-based inkjet printing technology. IEEE Trans. Inf. Technol. Biomed. 2012, 6, 1043-1050. [CrossRef] [PubMed]

6. Beni, V.; Nilsson, D.; Arven, P.; Norberg, P.; Gustafsson, G.; Turner, A.P.F. Printed Electrochemical Instruments for Biosensors. ECS J. Solid State Sci. Technol. 2015, 4, S3001-S3005. [CrossRef]

7. Bezuidenhout, P.H.; Land, K.J.; Joubert, T.-H. Integrating integrated circuit chips on paper substrates using inkjet-printed electronics. In Proceedings of the 17th Annual International conference of the Rapid Product Development Association of South-Africa, VUT Southern Gauteng Science and Technology Park, Vanderbijlpark, South Africa, 2-4 November 2016.

8. Smith, S.; Bezuidenhout, P.; Mbanjwa, M.; Zheng, H.; Conning, M.; Palaniyandy, N.; Ozoemena, K.; Land, K. Development of paper-based electrochemical sensors for water quality monitoring. In Proceedings of the Fourth Conference on Sensors, MEMS and Electro-Optic Systems, International Society for Optics and Photonics, Skukuza, South Africa, 12-14 September 2017.

9. Trnovec, B.; Stanel, M.; Hahn, U.; Hübler, A.C.; Kempa, H.; Sangl, R. Coated paper for printed electronics. Prof. Papermak. 2009, 6, 48-51.

10. Printed Electronics World. Available online: https://www.printedelectronicsworld.com/journal/printarticles.asp? articleids $=4251$ (accessed on 7 April 2017).

11. Chansin, G. Printed and Flexible Sensors: From Healthcare to IoT; IDTechEX Webinar: Cambridge, UK, 2017. 
12. Tao, H.; Brenckle, M.A.; Yang, M.; Zhang, J.; Liu, M.; Siebert, S.M.; Averitt, R.D.; Mannoor, M.S.; McAlphine, M.C.; Rogers, J.A.; et al. Silk-based conformal, adhesive, edible food sensors. Adv. Mater. 2012, 24, 1067-1072. [CrossRef] [PubMed]

13. Le Borgne, B.; De Sagazan, O.; Crand, S.; Jacques, E.; Harnois, M. Conformal Electronics Wrapped Around Daily Life Objects Using an Original Method: Water Transfer Printing. ACS Appl. Mater. Interfaces 2017, 9, 29424-29429. [CrossRef] [PubMed]

14. Bezuidenhout, P.; Smith, S.; Land, K.; Joubert, T.-H. A low-cost potentiostat for point-of-need diagnostics. In Proceedings of the 13th Edition of IEEE AFRICON, Cape Town, South Africa, 18-20 September 2017.

15. Bezuidenhout, P.; Smith, S.; Land, K.; Joubert, T. Hybrid paper-based potentiostat for low-cost point-of-need diagnostics. In Proceedings of the 21st International Conference on Miniaturized Systems for Chemistry and Life Sciences, Savannah, GA, USA, 22-26 October 2017.

16. Jo, Y.; Oh, S.; Lee, S.S.; Seo, Y.-H.; Ryu, B.-H.; Moon, J.; Choi, Y.; Jeong, S. Extremely flexible, printable Ag conductive features on PET and paper substrates via continuous millisecond photonic sintering in a large area. J. Mater. Chem. C 2014, 2, 9746-9753. [CrossRef]

17. Kounaves, S.P. Voltammetric Techniques. In Handbook of Instrumental Techniques for Analytical Chemistry, 2nd ed.; Prentice Hall PTR: Upper Saddle River, NJ, USA, 1997; pp. 709-725.

18. Zou, Z.; Jang, A.; McKnight, E.; Wu, P.-M.; Do, J.; Bishop, P.; Ahn, C. Environmentally friendly disposable sensors with microfabricated on-chip planar bismuth electrode for in situ heavy metal ions measurement. Sens. Actuators B Chem. 2008, 134, 18-24. [CrossRef]

19. Sung, G.-N.; Chen, W.-C.; Kuo, C.-T.; Chue, J.-J.; Wu, C.-M.; Huang, C.-M.; Chen, C.-C. A wireless and batteryless intelligent carbon monoxide sensor. Sensors 2016, 16, 1568.

20. Mostafalu, P.; Lenk, W.; Dokmeci, M.R.; Ziaie, B.; Khademhosseini, A.; Sonkusale, S.R. Wireless flexible smart bandage for continuous monitoring of wound oxygenation. IEEE Trans. Biomed. Circ. Syst. 2015, 9, 670-677. [CrossRef] [PubMed]

21. Basilotta, F.; Riario, S.; Stradolini, F.; Taurino, I.; Demarchi, D.; De Micheli, G.; Carrara, S. Wireless monitoring in intensive care units by a 3D-Printed system with embedded electronics. In Proceedings of the 2015 IEEE Biomedical Circuits and Systems Conference (BioCAS), Atlanta, GA, USA, 22-24 October 2015.

22. Jasinski, G.; Strzelczyk, A.; Koscinski, P. Low cost electrochemical sensor module for measurement of gas concentration. In Proceedings of the 39th International Microelectronics and Packaging, Gdansk, Poland, 20-23 September 2015.

23. Marinov, M.B.; Topalov, I.; Gieva, E.; Nikolov, G. Air quality monitoring in urban environments. In Proceedings of the 39th International Spring Seminar on Electronics Technology, Pilsen, Czech Republic, 18-22 May 2016.

24. Kaushik, A.; Yndart, A.; Dev Jayant, R.; Sagar, V.; Atluri, V.; Bhansali, S.; Nair, M. Electrochemical sensing method for point-of-care cortisol detection in human immunodeficiency virus-infected patients. Int. J. Nanomed. 2015, 10, 677-685.

25. Bezuidenhout, P.; Land, K.; Joubert, T.-H. A low-power CMOS operational amplifier IC for a heterogeneous paper-based potentiostat. In Proceedings of the Fourth Conference on Sensors, MEMS and Electro-Optic Systems, International Society for Optics and Photonics, Skukuza, South Africa, 12-14 September 2017.

26. Miettinen, J.; Pekkanen, V.; Kaija, K.; Mansikkamaki, P.; Mantysalo, J.; Mantysalo, M.; Niittynen, J.; Pekkanen, J.; Saviauk, T.; Ronkka, R. Inkjet printed System-in-Package design and manufacturing. Microelectron. J. 2008, 39, 1740-1750. [CrossRef]

27. Dickens, J.; Swart, H. BEETLE-A modular electronics family for robotics. In Proceedings of the Pattern Recognition Association of South Africa and Robotics and Mechatronics International Conference, Port Elizabeth, South Africa, 26-27 November 2015.

28. Raspberry Pi. Available online: https://www.raspberrypi.org/ (accessed on 10 December 2017).

29. Arduino. Available online: https://www.arduino.cc/ (accessed on 10 December 2017).

30. Harnett, C. Open source hardware for instrumentation and measurement. IEEE Instrum. Meas. Mag. 2011, 11, 34-38. [CrossRef]

31. Norena, N.; Kaushik, A.; Bhansali, S.; Cruz, A. A low-cost miniaturised potentiostat for point-of-care diagnosis. Biosens. Bioelectron. 2014, 62, 249-254.

32. Digi-Ivy. Available online: http:/ / www.digi-ivy.com/dy_pdfs/US_pricelist_en.pdf (accessed on 7 April 2018). 
33. Gobetwino MikMo. Available online: http://mikmo.dk/gobetwinodownload.html (accessed on 10 December 2017).

34. Princeton Applied Research. A Review of Techniques for Electrochemical Analysis; Application Note E-4; Princeton Applied Research: Oak Ridge, TN, USA, 2005.

35. PalmSens. Available online: https://www.palmsens.com/product/palmsens3/ (accessed on 10 December 2017).

36. Uduc8s.tv. Available online: http://educ8s.tv/tutorials/best-arduino-display/ (accessed on 7 April 2018).

37. RobotShop. Available online: https://www.robotshop.com/en/catalogsearch/result/?q=9V+battery\& order=relevance\&dir=desc (accessed on 7 April 2018).

38. National Research Fund. Available online: http://eqdb.nrf.ac.za/equipment/other/metrohm-autolabpgstat-302n (accessed on 10 December 2017).

39. RS Components (SA). Available online: https://za.rs-online.com/web/p/analogue-development-kits / 7972312/ (accessed on 7 April 2018).

40. AliExpress. Available online: https://www.aliexpress.com/w/wholesale-arduino-uno.html (accessed on 7 April 2018).

41. Central Circuits. Available online: http://www.ccza.com/quote_order_form.htm (accessed on 7 April 2018).

42. PayScale. Available online: https://www.payscale.com/research/ZA/Job=Research_Engineer/Salary (accessed on 7 April 2018).

(C) 2018 by the authors. Licensee MDPI, Basel, Switzerland. This article is an open access article distributed under the terms and conditions of the Creative Commons Attribution (CC BY) license (http://creativecommons.org/licenses/by/4.0/). 